\title{
Post-exercise T2 prolongation and recovery kinetics of upper arm muscles in non-athletes and athletes
}

\author{
Popadic Gacesa JZ ${ }^{1,2 *}$, Barak $\mathrm{O}^{1,2}$, Klasnja $\mathrm{A}^{1,2}$, Koprivsek $\mathrm{K}^{3}$, Kozic $\mathrm{D}^{3}$ and Semnic $\mathrm{R}^{3}$ \\ ${ }^{1}$ Department of Physiology, Faculty of Medicine, University of Novi Sad, Novi Sad, Serbia \\ ${ }^{2}$ Faculty of Sport and Physical Education, University of Novi Sad, Novi Sad, Serbia \\ ${ }^{3}$ Center for Imaging Diagnostics, Institute of Oncology, Sremska Kamenica, Serbia
}

Images were presented in the Conference: Joint meeting of national physiological societies "New perspectives in physiological research -young investigator forum" which was held from 25-27 $7^{\text {th }}$ May 2017 in Subotica, Serbia.

Post-exercise $T_{2}$ prolongation and recovery kinetics of upper arm muscles in non-athletes and athletes

Figure 1 is showing relaxometric maps of the right upper arm of non-athlete and athlete, depicting the time course of exercise induced changes (concentric elbow flexion exercise to failure - weight lifting with $75 \%$ of $1 \mathrm{RM}$ ). $\mathrm{T}_{2}$ maps acquired before exercise, immediately after exercise and 30min and 60min later during recovery are shown.

Protocol: prone position, transverse mid-humerus upper arm images (slice thickness 10mm, FoV 256x512, matrix size 256x128) were obtained by using a multiple spin-echo sequence with TR-2520ms, TE$10,20,30,40,50,60,70,80,90,100,110,120,130,140,150,160 \mathrm{~ms}$ on the Magnetom Aera TIM Siemens (Siemens, Erlangen, Germany). T2 time values before, immediately after exercise, as well as after $30 \mathrm{~min}$ and $60 \mathrm{~min}$ of recovery were calculated from automatically generated T2 maps in the whole muscle area on the scanner.

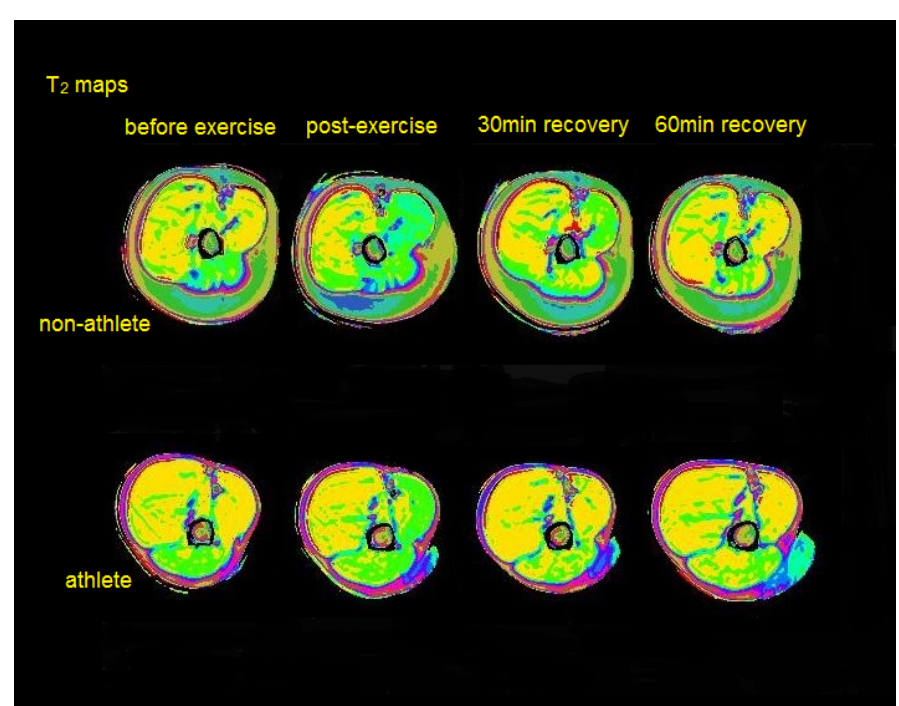

Figure 1. Relaxometric maps of the right upper arm of non-athlete and athlete, depicting the time course of exercise induced changes (concentric elbow flexion exercise to failure - weight lifting with $75 \%$ of $1 \mathrm{RM}$ ). $\mathrm{T}_{2}$ maps acquired before exercise, immediately after exercise and $30 \mathrm{~min}$ and $60 \mathrm{~min}$ later during recovery are shown.
Post-processing was obtained by using MIPAV software [1]. Color change in active regions of m.biceps brachii immediately after exercise, as well as $30 \mathrm{~min}$ and $60 \mathrm{~min}$ after exercise corresponds to $\mathrm{T}_{2}$ time prolongation and recovery. In non-athlete, $\mathrm{T}_{2}$ recovery with returning to baseline values in m.biceps area was noticed after $60 \mathrm{~min}$ recovery. In athlete, post-exercise $\mathrm{T}_{2}$ prolongation value in m.biceps area was twice lower than in non-athlete with same relative exercise intensity, and it reestablished baseline values faster, after only $30 \mathrm{~min}$ of recovery.

Comparing $\mathrm{T}_{2}$ prolongation and recovery kinetics in athletes and non-athletes could provide additional information on metabolic changes in exercising muscle as well as muscle activation patterns in the light of previous exercise history, which could improve treatment strategies for training and rehabilitation exercise protocols [2-4].

\section{Acknowledgements}

The study was supported by the Ministry of Science and Technological Development, Republic of Serbia, Project: Muscular and neural factors of human locomotion and their adaptation, number: 175037.

We would like to gratefully acknowledge valuable expertise of Dr. sc. hum. Dipl. Phys. Petros Martirosian, from the Section on Experimental Radiology, Department of Diagnostic and Interventional Radiology, University Hospital Tübingen, Tübingen, Germany, who designed protocol MR sequence used in this research.

\section{References}

1. McAuliffe M, Lalonde F, McGarry D, Gandler W, Csaky K et.al (2001) Medical imaging processing, analysis \& visualization in clinical research. IEEE Computerbased Medical Systems 381-386.

2. Haddock B, Holm S, Poulsen JM, Enevoldsen LH, Larsson HBW et.al (2016) Assessment of muscle function using hybrid PET/MRI: comparison of ${ }^{18} \mathrm{~F}-\mathrm{FDG}$ PET and $\mathrm{T}_{2}$-weighted MRI for quantifying muscle activation in human subjects. Eur $\mathrm{J} \mathrm{Nucl}$ Med Mol Imaging 44: 704-711. [Crossref]

Correspondence to: Jelena Z Popadic Gacesa, Department of Physiology, Faculty of Medicine, University of Novi Sad, Hajduk-Veljko St-21000 Novi Sad, Serbia, Tel: +381 216624 163; E-mail: jpopadic@uns.ac.rs and jelena.popadic-gacesa@ mf.uns.ac.rs

Key words: T2 relaxometry, m.biceps brachii, athletes

Received: February 20, 2018; Accepted: March 03, 2018; Published: March 10, 2018 
Popadic Gacesa JZ (2018) Post-exercise T2 prolongation and recovery kinetics of upper arm muscles in non-athletes and athletes

3. Hug F, Marqueste T, Le Fur Y, Cozzone PJ, Grelot L et.al (2006) Selective traininginduced thigh muscles hypertrophy in professional road cyclists. Eur J Appl Physiol 97: 591-597. [Crossref]
4. Varghese J, Scandling D, Joshi R, Aneja A, Craft J et.al (2015) Rapid assessment of quantitative $\mathrm{T}_{1}, \mathrm{~T}_{2}$ and $\mathrm{T}_{2} *$ in lower extremity muscles in response to maximal treadmill exercise. NMR Biomed 28: 998-1008. [Crossref]

Copyright: (C2018 Popadic Gacesa JZ. This is an open-access article distributed under the terms of the Creative Commons Attribution License, which permits unrestricted use, distribution, and reproduction in any medium, provided the original author and source are credited. 